\title{
Czochralski growth techniques of germanium crystals grown from a melt covered partially or fully by liquid $\mathrm{B}_{2} \mathrm{O}_{3}$
}

Toshinori Taishi $^{\mathrm{a},{ }^{*}}$, Yoshio Hashimoto ${ }^{\mathrm{b}}$, Hideaki Ise ${ }^{\mathrm{c}}$, Yu Murao $^{\mathrm{c}}$, Takayuki Ohsawa $^{\mathrm{c}}$, Ichiro Yonenaga $^{\mathrm{c}}$

${ }^{a}$ Institute of Carbon Science and Technology, Shinshu University, Nagano 380-8553, Japan

${ }^{\mathrm{b}}$ Faculty of Engineering, Shinshu University, Nagano 380-8553, Japan

${ }^{\mathrm{c}}$ Institute for Materials Research, Tohoku University, Sendai 980-8577, JAPAN

We propose two unique Czochralski (CZ) techniques for growing germanium $(\mathrm{Ge})$ crystals with an extremely low dislocation density and high interstitial oxygen concentration ([Oi]) using boron oxide $\left(\mathrm{B}_{2} \mathrm{O}_{3}\right)$ and a silica crucible. When a Ge melt is partially covered with liquid $\mathrm{B}_{2} \mathrm{O}_{3}$, but only on the outer region of the melt surface, germanium-oxide $\left(\mathrm{GeO}_{2}\right)$-related particles forming naturally in the melt are effectively dissolved by the liquid $\mathrm{B}_{2} \mathrm{O}_{3}$. The clean central portion of the melt produces dislocation-free undoped or Ga-doped Ge crystals. In addition, Ge crystals with [Oi] up to $6 \times 10^{17} \mathrm{~cm}^{-3}$ can be grown from a melt fully covered by liquid $\mathrm{B}_{2} \mathrm{O}_{3}$ with added $\mathrm{GeO}_{2}$ powder. The reaction and transportation of oxygen atoms during the growth process using $\mathrm{B}_{2} \mathrm{O}_{3}$ was investigated, revealing that liquid $\mathrm{B}_{2} \mathrm{O}_{3}$ acts like a catalyst without heavy contamination of the growing Ge crystal by B and Si atoms.

PACS CODE: PACS: 81.10.Fq; 61.72.Ff; 61.72.uf

Keywords: A1. Doping, A1. Impurities, A2. Single crystal growth, A2. Czochralski method, A2. Liquid encapsulated Czochralski method, B2. Semiconducting germanium 
*Corresponding author: Tel.: +81-26-269-5383, Fax.: +81-26-269-5388

E-mail address: taishi@shinshu-u.ac.jp (T. Taishi) 


\section{Introduction}

Bulk germanium $(\mathrm{Ge})$ crystals are currently in practical use as lens and window materials for infrared optical systems and as substrates for GaAs solar cells [1]. In particular, Ge can be used as the bottom cells of III-V-based triple-junction tandem solar cells for space use, and conversion efficiency as high as $41.1 \%$ has been reported under focused sunlight [2]. For such uses, Ge must be free from dislocations to avoid their negative influence as severe carrier killers in the bottom cell or the upper III-V epitaxial layers. This means that Ge crystals become more commercially desirable the closer they come to being dislocation-free.

Ge crystals are generally grown by the Czochralski (CZ) method using a graphite crucible in a vacuum or inert gas $\left(\mathrm{N}_{2}\right.$ or $\left.\mathrm{Ar}\right)$ atmosphere [3]. Recently, dislocation-free Ge single crystals up to $300 \mathrm{~mm}$ in diameter have been grown by Umicore Corporation [1]. In addition, the growth of high quality Ge crystals by the vertical Bridgman (VB) [4] and the vertical gradient freeze (VGF) techniques [5,6] has also been reported. One of the common outcomes of these techniques is that the interstitial oxygen concentration ([Oi]) in the Ge crystals is very low. It is well known that germanium oxide $\left(\mathrm{GeO}_{2}\right)$-related particles coming from residual oxygen in the growth furnace are easily formed on the melt surface. They then attach to the growing Ge crystal surface, finally generating dislocations in the crystal around these locations. Oxygen-enriched Ge crystals can be grown under an oxygen-containing atmosphere using a silica crucible or ampoule [7-10]. Indeed, the maximum concentration of interstitially dissolved oxygen in Ge crystals grown by such a method is reported to be $7 \times 10^{17} \mathrm{~cm}^{-3}$ [7], although the quality of the grown crystal is not good, the dislocation density in the crystal is high. Generally, Si atoms (contaminants from the silica 
container) have been detected in such grown crystals by infrared spectroscopy [9-11].

In the case of CZ-Si crystal growth, a silica crucible is generally used, and therefore oxygen atoms are enriched in the grown crystals. At present, CZ-Si crystals containing oxygen atoms at a concentration of $\sim 10^{18} \mathrm{~cm}^{-3}$ are used exclusively in industry on account of their high critical resolved shear stress for dislocation generation [12] and high mechanical strength in comparison with float-zone Si crystals [13]. Basically, oxygen impurities interstitially dissolved in Si crystals have been found to preferentially segregate on and immobilize dislocations, leading to high mechanical stability of the crystal [14]. In the case of Ge, a similar phenomenon produced by oxygen doping was recently reported [15], and application in solar cells and other electric devices using such Ge crystals with high mechanical strength is expected in the near future.

On the other hand, III-V semiconductors such as GaAs, GaP and InP have been grown by the liquid encapsulated Czochralski (LEC) technique [16-18]. Generally, boron oxide $\left(\mathrm{B}_{2} \mathrm{O}_{3}\right)$ has been used as a stable and suitable liquid encapsulant. The evaporation of volatile elements such as As and $\mathrm{P}$ can be suppressed by a $\mathrm{B}_{2} \mathrm{O}_{3}$ layer constructed on the compound melt surface. In these cases, free boron atoms are formed by the dissolution of $\mathrm{B}_{2} \mathrm{O}_{3}$ and some of them incorporate into the grown crystals. However, almost all B atoms that are incorporated replace a Ga or In at a site in their sphalerite structure, and are electrically inactive in the crystals.

In this paper, we report two $\mathrm{CZ}$ techniques for growing Ge crystals from a melt covered by liquid $\mathrm{B}_{2} \mathrm{O}_{3}$. First, a unique $\mathrm{CZ}$ technique for growing dislocation-free $\mathrm{Ge}$ crystals using $\mathrm{B}_{2} \mathrm{O}_{3}$ is presented. Second, growth from a melt fully covered by liquid $\mathrm{B}_{2} \mathrm{O}_{3}$, similar to LEC growth, is introduced. Oxygen-containing Ge crystals with low dislocation densities can be obtained from 
such a melt by the intentional addition of $\mathrm{GeO}_{2}$ powder to the melt. The chemical and electrical properties of the Ge crystal evaluated showed that contamination levels of B and Si atoms in the crystal were very low, and these aspects of the technique are discussed.

\section{Growth of Ge crystals from a melt partially covered by liquid $\mathrm{B}_{2} \mathrm{O}_{3}$}

Ge ingots $(\sim 150 \mathrm{~g})$ were charged in a silica crucible $50 \mathrm{~mm}$ in diameter, and $\mathrm{B}_{2} \mathrm{O}_{3}$ chunks $(5 \mathrm{~g}$ or $7.5 \mathrm{~g}$ ) were placed on the Ge ingots. [111] or [001]-oriented Ge crystals 1 inch in diameter were grown by the $\mathrm{CZ}$ method at a pulling rate of $10 \mathrm{~mm} / \mathrm{h}$ at $1 \mathrm{~atm}$ in an Ar atmosphere. Detailed growth conditions were described previously [19]. For comparison, two Ge crystals were grown under the same conditions: one grown normally from a Ge melt but without any liquid $\mathrm{B}_{2} \mathrm{O}_{3}$, another grown from a melt with added $\mathrm{B}_{2} \mathrm{O}_{3}$ chunks $(5 \mathrm{~g})$ and $\mathrm{GeO}_{2}$ powder $(0.04$ at $\%$ in melt $)$ with a purity of $5 \mathrm{~N}$. Ga-doped Ge crystals with a Ga concentration up to $6 \times 10^{17} \mathrm{~cm}^{-3}$ were also grown with and without liquid $\mathrm{B}_{2} \mathrm{O}_{3}$ under the same conditions.

After melting $\mathrm{B}_{2} \mathrm{O}_{3}$ chunks at $480^{\circ} \mathrm{C}$ and $\mathrm{Ge}$ ingots at $938^{\circ} \mathrm{C}$, only the outside region of the Ge melt was covered with the liquid $\mathrm{B}_{2} \mathrm{O}_{3}$ in a silica crucible [19]. No particles to hinder dislocation-free crystal growth were observed in the melt. Finally, a clean and particle-free Ge melt surface was produced in the central region of the crucible, making it possible to grow from a "clean" Ge melt. Figure 1 (a) illustrates the present crystal growth technique from such a melt.

Figure 1 (b) shows a [001]-oriented undoped Ge crystal grown from a Ge melt partially covered with $\mathrm{B}_{2} \mathrm{O}_{3}$. It has a diameter of about 1 inch and a length of about $50 \mathrm{~mm}$. No grain boundary is observed in the entire crystal until the tail, and no particles are detected on the surface 
of the crystal. Four habit lines can be clearly observed. The crystal growth procedure was almost the same as that in the conventional method except that the Ge melt was partially covered with $\mathrm{B}_{2} \mathrm{O}_{3}$ liquid. The dislocation density at the top of the crystal shown in Fig. 1 (b) was evaluated by preferential etching using a solution of $1 \mathrm{HF}+1 \mathrm{H}_{2} \mathrm{O}_{2}+4 \mathrm{H}_{2} \mathrm{O}$ [20] for [001]-oriented crystals or Billig etchant [21] for [111]-oriented crystals, both for comparison with that of a Ge crystal grown by the conventional CZ method. Figures 2 (a) and (b) show optical micrographs of a Ge crystal grown by the present technique and by the conventional $\mathrm{CZ}$ method, respectively. No etch pits are observed in Fig. 2 (a). In contrast, in the conventionally grown Ge crystal, many rectangular etch pits of about $8 \times 10^{3} \mathrm{~cm}^{-2}$ were observed (Fig 2 (b)), with dislocation density higher at the periphery than in the central region. The present work shows that the dislocation density in a Ge crystal can be considerably reduced by using the technique of partially- $\mathrm{B}_{2} \mathrm{O}_{3}$-covered $\mathrm{CZ}-\mathrm{Ge}$ growth. Etch pits could also not be detected in [111]-oriented undoped and Ga-doped Ge crystals with a Ga concentration up to $6 \times 10^{17} \mathrm{~cm}^{-3}$. These results indicate that the growth of Ge crystals from a partially- $\mathrm{B}_{2} \mathrm{O}_{3}$-covered melt is also effective for any orientation and for, at least, undoping and $\mathrm{Ga}$ doping. The detailed results for Ga doping will be reported elsewhere.

The carrier concentration in the top portion of the as-grown undoped crystal after annealing at $550{ }^{\circ} \mathrm{C}$ with subsequent cooling to RT for annihilation of oxygen-related thermal donors (OTD) [10] was $1 \times 10^{14} \mathrm{~cm}^{-3}$. The crystal kept n-type conduction before and after donor annihilation. The B concentration in the crystals as evaluated by SIMS analysis was lower than the detection limit of $2 \times 10^{15} \mathrm{~cm}^{-3}$. These findings indicate that the contamination of the crystal by B atoms was very low, at least lower than the carrier concentration after donor annihilation. 
In order to confirm that particles were not formed, or were caught or dissolved by the liquid $\mathrm{B}_{2} \mathrm{O}_{3}$, powdered $\mathrm{GeO}_{2}$ was intentionally added at 0.04 at $\%$ to the partially- $\mathrm{B}_{2} \mathrm{O}_{3}$-covered melt and a crystal was grown from the melt. The added $\mathrm{GeO}_{2}$ powder completely disappeared when the $\mathrm{Ge}$ starting materials were fully melted, and in this way a particle-free Ge melt was produced at the central position. The dislocation density in the crystal grown from this melt was $5 \times 10^{2} \mathrm{~cm}^{-2}$, lower than that in an undoped crystal, in spite of the intentional addition of $\mathrm{GeO}_{2}$ powder. Therefore, it is likely that any $\mathrm{GeO}_{2}$-related particles that may form in the Ge melt during crystal growth dissolve when liquid $\mathrm{B}_{2} \mathrm{O}_{3}$ is present.

\section{Growth of Ge crystals from a melt fully covered by liquid $\mathrm{B}_{2} \mathrm{O}_{3}$}

Ge ingots $(\sim 150 \mathrm{~g})$ were charged in a silica crucible, as for the partially- $\mathrm{B}_{2} \mathrm{O}_{3}$-covered melt, and $\mathrm{B}_{2} \mathrm{O}_{3}$ chunks weighing $20 \mathrm{~g}$ were placed on the Ge ingots. $\mathrm{GeO}_{2}$ powder $(0 \sim 0.42$ at $\%$ in melt $)$ with a purity of $5 \mathrm{~N}$ was intentionally added in the crucible with the $\mathrm{Ge}$ ingots and $\mathrm{B}_{2} \mathrm{O}_{3}$ chunk. Five [111]-oriented Ge crystals 1 inch in diameter were grown at a pulling rate of $10 \mathrm{~mm} / \mathrm{h}$. Detailed growth conditions were comparable to those for growth from the partially- $\mathrm{B}_{2} \mathrm{O}_{3}$-covered melt. In these procedures, the intentional formation of a neck portion for the complete elimination of dislocations generated by thermal shock was not carried out.

In all procedures, Ge melts were fully covered by liquid $\mathrm{B}_{2} \mathrm{O}_{3}$. With the intentional addition of $\mathrm{GeO}_{2}$ powder, the $\mathrm{Ge}$ melt below the $\mathrm{B}_{2} \mathrm{O}_{3}$ layer was obscured by cloudiness at first, but could be seen below a clear layer of $\mathrm{B}_{2} \mathrm{O}_{3}$ after stirring the layer by rotating the seed before initiating growth. Ge crystals could be grown through the $\mathrm{B}_{2} \mathrm{O}_{3}$ layer as shown in Fig. 3(a). A [111]-oriented Ge 
crystal shown in Fig. 3(b) was grown from fully- $\mathrm{B}_{2} \mathrm{O}_{3}$-covered melt with the intentional addition of $\mathrm{GeO}_{2}$ powder at 0.20 at $\%$. Any attachment or inclusion of $\mathrm{GeO}_{2}$-related particles or $\mathrm{B}_{2} \mathrm{O}_{3}$ solid would have occurred on the crystal surface, but the surface was very clean. Three habit lines were identified on the crystal surface, except for the crystal grown with the highest $\mathrm{GeO}_{2}$ powder addition of 0.42 at\% (leading to a twin). Dislocation densities in the top portion of grown crystals evaluated by preferential etching using Billig etchant [21] were less than $3 \times 10^{3} \mathrm{~cm}^{-2}$. In the crystal shown in Fig. 3(b), grown with intentional addition of $\mathrm{GeO}_{2}$ powder at 0.20 at $\%$, the dislocation density was lower than $5 \times 10^{2} \mathrm{~cm}^{-2}$.

The carrier concentration in as-grown crystals increased with increasing $\mathrm{GeO}_{2}$ powder addition in melts, from $7 \times 10^{14}$ to $2 \times 10^{16} \mathrm{~cm}^{-3}$. The origin of such carriers was based on OTDs [22], and could be annihilated by post-annealing at $550{ }^{\circ} \mathrm{C}$ for $1 \mathrm{~h}$ with subsequent cooling to RT. All crystals were n-type conduction before and after annealing, and the B concentration in all crystals was lower than the detection limit of SIMS analysis of $2 \times 10^{15} \mathrm{~cm}^{-3}$.

The interstitial oxygen concentration [Oi] in Ge as-grown crystals was evaluated by infrared absorption band at $855 \mathrm{~cm}^{-1}$ due to the antisymmetric $\left(v_{3}\right)$ stretching mode at RT using the calibration coefficient of $1.05 \times 10^{17} \mathrm{~cm}^{-2}$ [10]. Detailed conditions for the evaluation have been reported previously [23]. Figure 4 shows the relationship between the [Oi] determined in eight crystals and their growth conditions, especially the amount of $\mathrm{GeO}_{2}$ powder added, and the inset shows typical infrared spectra of Ge crystals around $855 \mathrm{~cm}^{-1}$. In crystals from the melts with no covering or partial covering by liquid $\mathrm{B}_{2} \mathrm{O}_{3}$, [Oi] was about $10^{16} \mathrm{~cm}^{-3}$. No remarkable enhancement of absorption peak height at $855 \mathrm{~cm}^{-1}$ could be detected when $\mathrm{GeO}_{2}$-powder was added to a 
partially- $\mathrm{B}_{2} \mathrm{O}_{3}$-covered melt. On the other hand, in crystals grown from a fully- $\mathrm{B}_{2} \mathrm{O}_{3}$-covered melt without the addition of $\mathrm{GeO}_{2}$ powder, [Oi] was at a similar level as in crystals grown from a partially- $\mathrm{B}_{2} \mathrm{O}_{3}$-covered melt, but it increased remarkably with increasing amounts of added $\mathrm{GeO}_{2}$ powder. When the amount of added $\mathrm{GeO}_{2}$ powder was 0.20 and 0.42 at $\%$, [Oi] in as-grown crystals was $5.5 \times 10^{17} \mathrm{~cm}^{-3}$. The [Oi] was enhanced to $6.2 \times 10^{17} \mathrm{~cm}^{-3}$ after annealing for OTD annihilation, and this was the highest value observed in crystals in the present study. However, both high [Oi] and low dislocation density were realized by growth from a fully- $\mathrm{B}_{2} \mathrm{O}_{3}$-covered melt with $\mathrm{GeO}_{2}$ powder added at 0.20 at $\%$. The total oxygen concentration in this crystal as analyzed by SIMS was $6.5 \times 10^{17} \mathrm{~cm}^{-3}$ and was comparable to the value obtained after OTD annihilation (within about $5 \%$ ), indicating that other oxygen-related precipitates such as $\mathrm{GeO}_{2}$ are very few in number and almost all oxygen atoms exist in interstitial sites in the Ge lattice.

As other remarkable features, we note that no absorption peaks were observed at $1106 \mathrm{~cm}^{-1}$, related to the $v_{3}$ stretching mode of $\mathrm{Si}-\mathrm{O}-\mathrm{Si}$ quasi-molecules or at $1225 \mathrm{~cm}^{-1}$, related to $\mathrm{SiO}_{2}$ precipitates, in any of the infrared spectra [23]. These indicate that $\mathrm{Si}-\mathrm{O}$-related defects were lower than the detection limits in all the Ge crystals.

\section{Reaction during crystal growth using liquid $\mathrm{B}_{2} \mathrm{O}_{3}$ and formation of free oxygen atoms}

Several experimental results lead us to suppose that the following phenomena took place during CZ-Ge crystal growth using liquid $\mathrm{B}_{2} \mathrm{O}_{3}$ : (i) $\mathrm{GeO}_{2}$-related particles or powder were dissolved by $\mathrm{B}_{2} \mathrm{O}_{3}$ liquid. (ii) Interstitial oxygen concentration ([Oi]) was slightly enhanced by some amount of $\mathrm{B}_{2} \mathrm{O}_{3}$ addition to the melt. (iii) [Oi] was dominantly enhanced up to $5.5 \times 10^{17} \mathrm{~cm}^{-3}$ (as-grown state) 
when more $\mathrm{GeO}_{2}$ powder was added. (iv) When the Ge melt was not fully covered by liquid $\mathrm{B}_{2} \mathrm{O}_{3}$ and $\mathrm{GeO}_{2}$ powder was added, [Oi] was not enhanced. (v) The level of Ge crystal contamination with B and Si atoms was very low.

Phenomena (i), (ii) and (iii) could be supported by the Gibbs standard free energy of the relevant oxides during crystal growth at the melting point of Ge [24]. The Gibbs standard free energy of $\mathrm{B}_{2} \mathrm{O}_{3}$ formation $(-6.50 \mathrm{~kJ} / \mathrm{mol})$ is lower than those of Ge-related oxides such as $\mathrm{GeO}$ $(-3.04 \mathrm{~kJ} / \mathrm{mol})$ and $\mathrm{GeO}_{2}(-3.41 \mathrm{~kJ} / \mathrm{mol})$ at the melting point of $\mathrm{Ge}$. In addition, $\mathrm{B}_{2} \mathrm{O}_{3}$ is thermodynamically stable, almost as much so as $\mathrm{SiO}_{2}(-6.80 \mathrm{~kJ} / \mathrm{mol})$. Assuming that free $\mathrm{B}$ atoms are formed from $\mathrm{B}_{2} \mathrm{O}_{3}$ near the $\mathrm{B}_{2} \mathrm{O}_{3} / \mathrm{Ge}$ melt interface, it can be understood that $\mathrm{GeO}_{2}$ particles are dissociated by the following reactions:

$$
\mathrm{B}_{2} \mathrm{O}_{3} \leftarrow \rightarrow 2 \mathrm{~B}+3 \mathrm{O}
$$

$$
3 \mathrm{GeO}_{2}+4 \mathrm{~B} \rightarrow 2 \mathrm{~B}_{2} \mathrm{O}_{3}+3 \mathrm{Ge}
$$

Here, free oxygen atoms are not formed by eq. (2), indeed, [Oi] is not enhanced when the melt is fully covered by liquid $\mathrm{B}_{2} \mathrm{O}_{3}$. However, [Oi] increased as more $\mathrm{GeO}_{2}$ powder was added. So we suppose that free oxygen atoms are formed during dissolution of some $\mathrm{GeO}_{2}$ molecules by free $\mathrm{B}$ atoms, as in the following equation:

$$
2 m \mathrm{GeO}_{2}+2 n \mathrm{~B} \rightarrow n\left(\mathrm{~B}_{2} \mathrm{O}_{3}\right)+2 m \mathrm{Ge}+(4 m-3 n) \mathrm{O}
$$


Finally, some quantity of the formed free oxygen atoms might segregate into a grown crystal. The highest oxygen level of $6.2 \times 10^{17} \mathrm{~cm}^{-3}$ (after OTD annihilation) obtained in the present study was comparable with that obtained by crystal growth using a silica crucible in oxygen-containing ambient $\left(7 \times 10^{17} \mathrm{~cm}^{-3}\right)$ [7]. This value may be the highest oxygen concentration in a Ge crystal obtained by the present growth techniques, although the maximum solid solubility of oxygen in Ge has been reported to be $2 \times 10^{18} \mathrm{~cm}^{-3}[8]$.

However, in phenomenon (iv), free oxygen atoms formed in the melt were lost from the partially- $\mathrm{B}_{2} \mathrm{O}_{3}$-covered melt. This indicates that the oxygen atoms evaporated from the melt window in the early stage of crystal growth. In other words, liquid $\mathrm{B}_{2} \mathrm{O}_{3}$ fully covering a Ge melt acts as a liquid encapsulant for free oxygen atoms formed by dissolution of $\mathrm{GeO}_{2}$ powder, as evaporation of volatile elements can be suppressed by a $\mathrm{B}_{2} \mathrm{O}_{3}$ layer in LEC growth. Therefore, full coverage of the Ge melt by $\mathrm{B}_{2} \mathrm{O}_{3}$ liquid and the addition of $\mathrm{GeO}_{2}$ are both key requirements for the enhancement of oxygen concentration in Ge crystals.

With regard to the contamination in Ge crystals related to phenomenon (v), chemical and electrical experiments revealed that the contamination level by B atoms in the melt was very low. As one of the reasons, the phase diagram of B and Ge is the monotectic type [25], implying that free $\mathrm{B}$ atoms in a $\mathrm{Ge}$ melt may be unstable. If $\mathrm{B}_{2} \mathrm{O}_{3}$ is significantly stable in the melt, the lifetime of free $\mathrm{B}$ atoms formed by dissociation of $\mathrm{B}_{2} \mathrm{O}_{3}$ (eq. (1)) in Ge melt should be very short. This is consistent with the experimental results.

However, the entry of $\mathrm{Si}$ atoms into the crystals could not be detected in infrared spectra. 
According to the Gibbs standard free energy, $\mathrm{SiO}_{2}$ is the most stable of the relevant oxides, but it is only slightly more stable than $\mathrm{B}_{2} \mathrm{O}_{3}$. Thus, while a reaction between $\mathrm{SiO}_{2}$ and $\mathrm{B}_{2} \mathrm{O}_{3}$ may occur, it will be very weakly driven near the $\mathrm{B}_{2} \mathrm{O}_{3} /$ silica crucible interface, yielding little product. Also, according to Si-doped LEC-GaAs growth, Si atoms doped in the melt are easily absorbed into the $\mathrm{B}_{2} \mathrm{O}_{3}$ layer [17]. A similar reaction may occur, and $\mathrm{Si}$ atoms dissolved from the silica crucible may easily be absorbed into the $\mathrm{B}_{2} \mathrm{O}_{3}$ layer in the present CZ-Ge crystal growth. More detailed investigations using other crucibles, such as those made from graphite or $\mathrm{pBN}$, are necessary and are now in progress.

In the present growth techniques, the addition of $\mathrm{B}_{2} \mathrm{O}_{3}$ and $\mathrm{GeO}_{2}$ powder leads to the growth of high quality Ge crystals with high mechanical strength. Liquid $\mathrm{B}_{2} \mathrm{O}_{3}$ acts like a convenient catalyst to prevent heavy contamination of the crystal by B and Si atoms during its growth. Such uncommon and fortuitous, but useful combinations as that of molten Ge and liquid $\mathrm{B}_{2} \mathrm{O}_{3}$ may also exist for growing other high-quality materials, such as metals, semiconductors, oxides and other functional crystals. The present techniques appear to be important early models of this, and more detailed investigation and analyses are indispensable. Although, the crystal size of Ge crystals shown in the present study is 1 inch in diameter and only an academic level, currently, as a next step, some trials for growing Ge crystals 2 inches in diameter using the present techniques are beginning. Such larger crystals with low dislocation density and high mechanical strength will be applicable for III-V solar cells with high conversion efficiency. Experimental results will be reported elsewhere in the near future. 


\section{Conclusion}

Two unique $\mathrm{CZ}$ techniques for growing Ge crystals with an extremely low grown-in dislocation density and high [Oi] using $\mathrm{B}_{2} \mathrm{O}_{3}$ and a silica crucible are described. There is hesitation to use silica crucibles and $\mathrm{B}_{2} \mathrm{O}_{3}$ for $\mathrm{CZ}$-Ge crystal growth because of the possibility the crystal will be contaminated with Si and B atoms. However, dislocation-free Ge crystals can be grown from a partially- $\mathrm{B}_{2} \mathrm{O}_{3}$-covered melt, and oxygen-enriched Ge crystals from a fully- $\mathrm{B}_{2} \mathrm{O}_{3}$-covered melt, in both cases with very little contamination from $\mathrm{Si}$ and $\mathrm{B}$ atoms. $\mathrm{GeO}_{2}$-related particles are dissolved by the liquid $\mathrm{B}_{2} \mathrm{O}_{3}$ that covers the molten $\mathrm{Ge}$, and [Oi] can be enhanced up to $6 \times 10^{17} \mathrm{~cm}^{-3}$ both by the intentional addition of $\mathrm{GeO}_{2}$ powder and fully covering the melt with liquid $\mathrm{B}_{2} \mathrm{O}_{3}$. Such uncommon and useful combinations as that of molten $\mathrm{Ge}$ and liquid $\mathrm{B}_{2} \mathrm{O}_{3}$ may also exist for growing other materials. High quality Ge crystals with large diameter grown using such techniques with high mechanical strength due to oxygen doping are expected to be used for solar cells or other electric devices in the near future.

\section{Acknowledgement}

This work was supported in part by a Grant-in-Aid for Science Research (20760003 and 22686002) from the Ministry of Education, Science, Sports and Culture. This work was also performed under the Inter-university Cooperative Research Program of the Institute for Materials Research, Tohoku University. 


\section{References}

[1] B. Depuydt, A. Theuwis, I. Romandic, Mater. Sci. Semicond. Process. 9 (2006) 437-443.

[2] W. Guter, J. Schone, S. P. Philipps, M. Steiner, G. Siefer, A. Wekkeli, E. Welser, E. Oliva, A. W. Bett, F. Dimoroth, Appl. Phys. Lett. 94 (2009) 223504 (1-3).

[3] B. Depuydt, M. Jonghe, W. Baets, Germanium-Based Technologies, ed. C. Claeys and E. Simoen (Elsevier, Oxford, UK) p17.

[4] M.P. Volz, J.S. Walker, M. Schweizer, S.D. Cobb, F.R. Szofran, J. Cryst. Growth 282 (2005) $305-312$

[5] C. Rotsch, P. Rudolph, J. Cryst. Growth 311 (2009) 2294-2299.

[6] D. Langheinrich, O.Pätzold, L.Raabe, M.Stelter, J. Cryst. Growth 312 (2010) 2291-2296.

[7] J. Bloem, C. Haas, P. Penning, J. Phys. Chem. Solids 12 (1959) 22-27.

[8] W. Kaiser, C. Thurmond, J. Appl. Phys. 32 (1961) 115-118.

[9] O. De Gryse, P. Vanmeerbeek, J. Vanhellemont, P. Clauws, Mater. Sci. Semicond. Process. 9 (2006) 246-251.

[10] V. V. Litvinov, B. G. Svensson, L. I. Murin, J. L. Lindström, V. P. Markevich, A. R. Peaker, J. Appl. Phys. 100 (2006) 033525 (1-5).

[11] P. Clauws, Mat. Sci. Eng. B36 (1996) 213-220.

[12] I. Yonenaga, T. Taishi, X. Huang, K. Hoshikawa, J. Appl. Phys. 89 (2001) 5788-5790.

[13] M. Imai, K. Sumino, Phil. Mag. A 47 (1983) 599-621.

[14] I. Yonenaga, K. Sumino, J. Appl. Phys. 80 (1996) 734-738.

[15] Y. Murao, T. Taishi, Y. Tokumoto, Y. Ohno, I. Yonenaga, J. Appl. Phys. 109 (2011) 113502 
$(1-5)$.

[16] J. B. Mullin, B. W. Straugham, W. S. Brickell, J. Phys. Chem. Solids 26 (1965) 782-784.

[17] C. Hannig, G. Schwichtenberg, E. Buhrig and G. Gärtner, Mater. Sci. Eng. B 66 (1999) 97-101.

[18] A. Seidl, S. Eichler, T. Flade, M. Jurisch, A. Kohler, U. Kretzer, B. Weinert, J. Cryst. Growth 225 (2000) 561-565.

[19] T. Taishi, Y. Ohno, I. Yonenaga, J. Cryst. Growth 311 (2009) 4615-4618.

[20] P. R. Camp, J. Electrochem. Soc. 108 (1955) 586-593.

[21] E. Billig, Proc. Roy. Soc. A 235 (1956) 37-55.

[22] T. Taishi, Y. Hashimoto, H. Ise, Y. Murao, T. Ohsawa, Y. Tokumoto, Y. Ohno, I. Yonenaga, J. Phys. Conf. Ser. 281 (2011) 012011 (1-6).

[23] T. Taishi, H. Ise, Y. Murao, T. Ohsawa, M. Suezawa, Y. Tokumoto, Y. Ohno, K. Hoshikawa, I. Yonenaga, J. Cryst. Growth 312 (2010) 2783-2787.

[24] I. Barin, Thermochemical Data of Pure Substances, Part I and Part II, VCH, Weinheim,1989.

[25] R.W. Olesinski, G.J. Abbaschian, in: T.B. Massalski (Ed.), Binary Alloy Phase Diagrams, II Ed., 1990, p. 486, vol. 1. 
Figure captions

Fig. 1 An illustration of Ge crystal growth from a melt partially covered by $\mathrm{B}_{2} \mathrm{O}_{3}$ and (b) a photograph of a [001]-oriented undoped Ge crystal grown as shown in (a).

Fig. 2 Optical micrographs of etch pits in [001]-oriented undoped Ge crystals (a) grown from partially- $\mathrm{B}_{2} \mathrm{O}_{3}$ - covered Ge melt and (b) grown by the conventional $\mathrm{CZ}$ method.

Fig. 3 An illustration of Ge crystal growth from a melt fully covered by $\mathrm{B}_{2} \mathrm{O}_{3}$ and (b) a photograph of a [111]-oriented Ge crystal grown as shown in (a). [Oi] in this as-grown crystal was $5.5 \times 10^{17}$ $\mathrm{cm}^{-3}$, and the etch pit density was less than $5 \times 10^{2} \mathrm{~cm}^{-2}$.

Fig. 4 A relationship between the [Oi] in eight crystals and their growth conditions, especially the amount of $\mathrm{GeO}_{2}$ powder added. The inset shows typical three infrared spectra of Ge crystals grown from fully- $\mathrm{B}_{2} \mathrm{O}_{3}$-covered melt with different amount of $\mathrm{GeO}_{2}$ powder addition around $855 \mathrm{~cm}^{-1}$. 


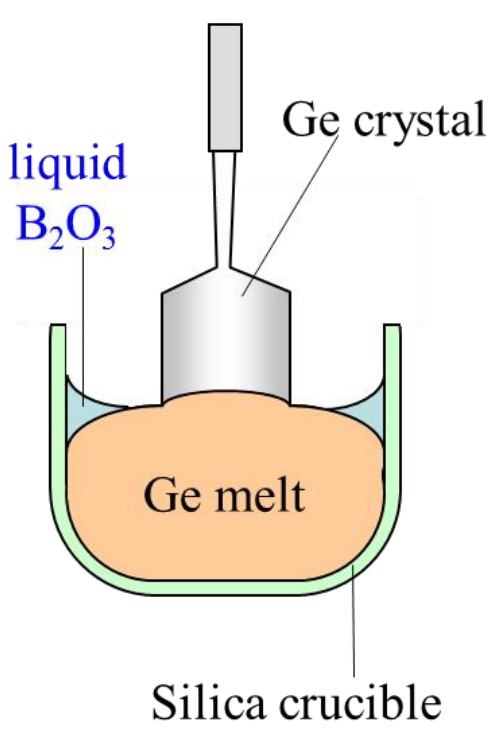

(a)

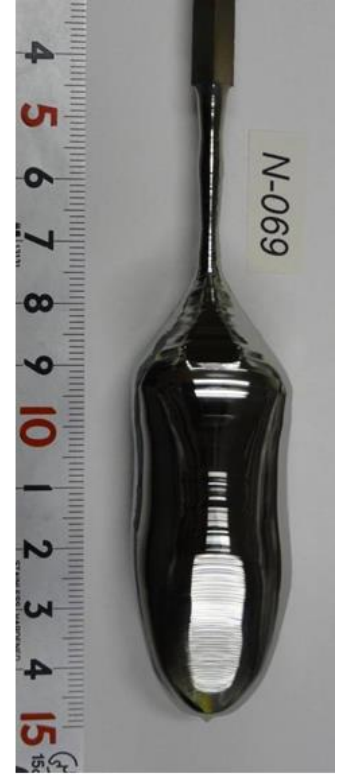

(b)

Fig. 1 


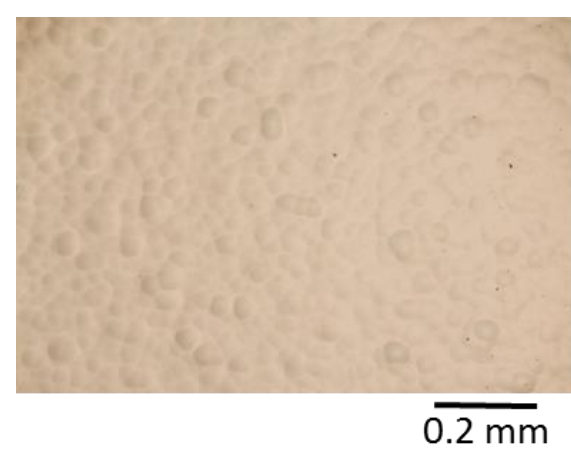

(a)

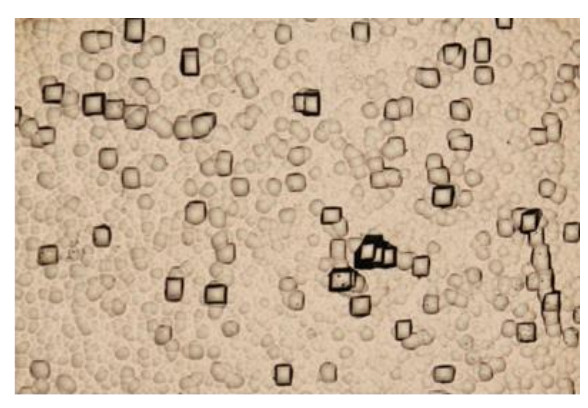

(b)

Fig. 2 


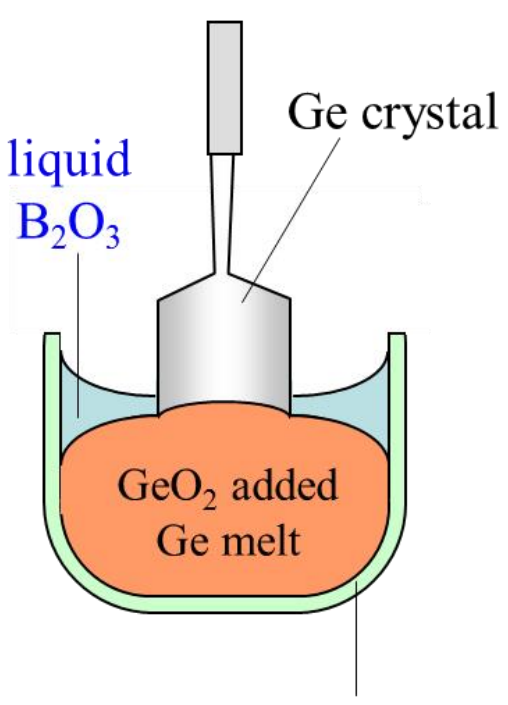

Silica crucible

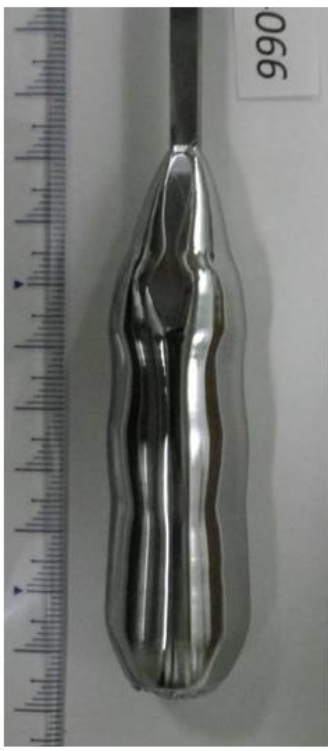

(b)

Fig. 3 


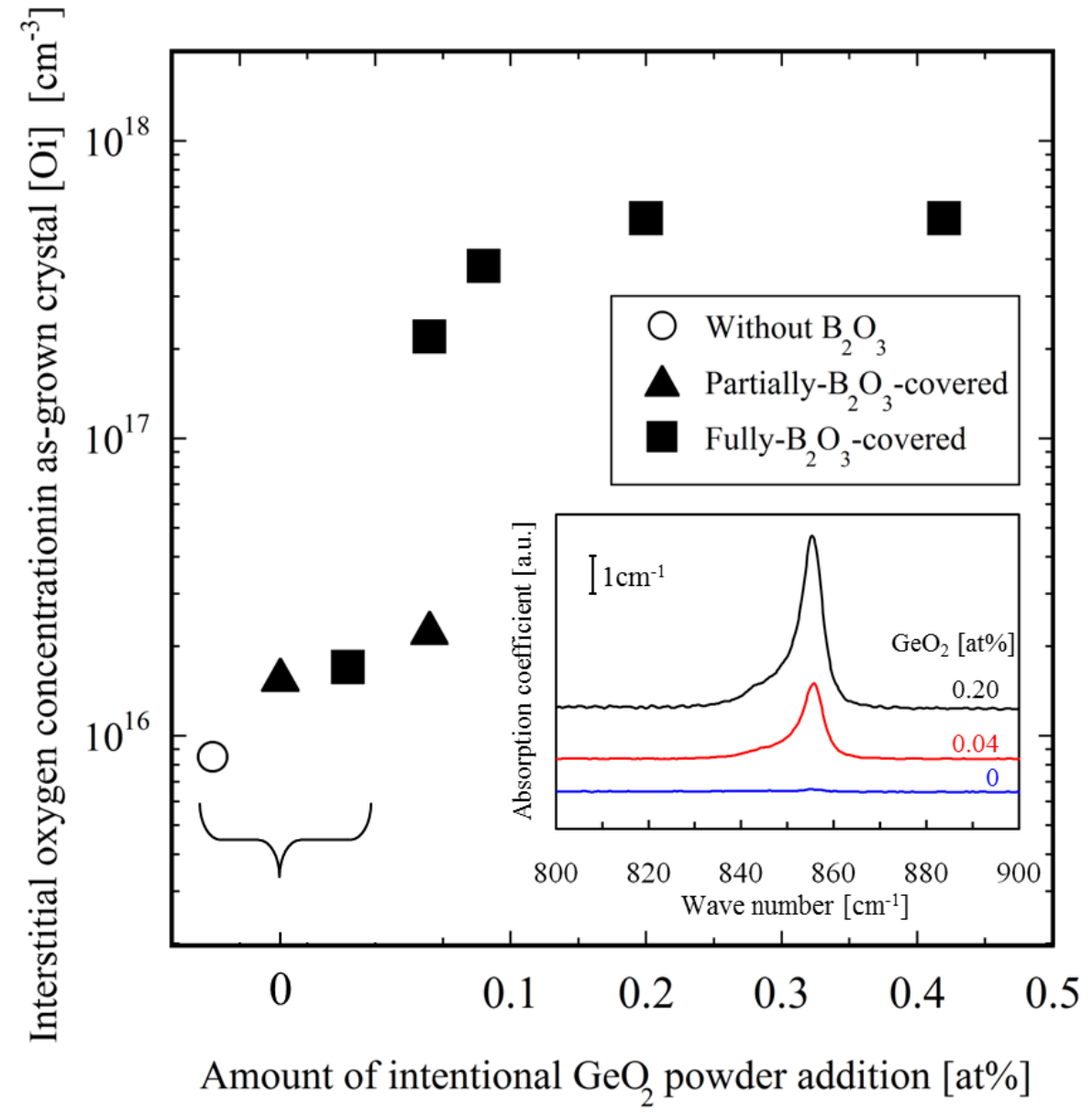

Fig. 4 